\title{
Incidence of Ostomies in Tertiary Care Teaching Institution
}

\author{
D. Devi Keerthana, A. Rekha \\ Saveetha Medical College, SIMATS Thandalam, Chennai, India \\ Email: devikeer tha nal6@gmail.co
}

How to cite this paper: Keerthana, D.D. and Rekha, A. (2019) Incidence of Ostomies in Tertiary Care Teaching Institution. Case Reports in Clinical Medicine, 8, 181-188.

https://doi.org/10.4236/crcm.2019.87022

Received: May 6, 2019

Accepted: July 8, 2019

Published: July 11, 2019

Copyright $\odot 2019$ by author(s) and Scientific Research Publishing Inc. This work is licensed under the Creative Commons Attribution International License (CC BY 4.0).

http://creativecommons.org/licenses/by/4.0/

\begin{abstract}
A retrospective observational study was conducted at Saveetha medical college and hospital, over 2 years, from January 2017-January 2019. A total of 29 patients with ostomies were included in this study. Information regarding the types and indications of the ostomies were collected from the hospital records. The collected data were analyzed using Microsoft Excel, and represented by tables and charts. Majority of patients were the males and the predominant age group was $51-60$ years old. The objective of the present study was to classify ostomies based on organs and to analyze the aetiology for creating those ostomies.
\end{abstract}

\section{Keywords}

Ostomies, Ileostomy, Jejunostomy, Colostomy, Indications, Malignancy

\section{Introduction}

Ostomies or stomas are a lifesaving procedure in which surgically an opening is created on the abdominal wall. Stoma comes from a Greek word meaning "opening" or "mouth". In World War One, mortality rate of $60 \%$ for primary repair of colonic injuries dropped to $30 \%$ in World War Two due to introduction of colostomy. In 1710, Littre of Paris was the first to make a ventral colostomy for a baby with imperforate anus. An ileostomy was first done in 1912 for ulcerative colitis but was widely used only after Brooke did his everted ileostomy in 1952. Stomas are used to divert faecal matter away from distal bowel for the distal anastomoses to heal or to relieve obstruction in emergency situation. Though it is a lifesaving procedure, carries significant number of complications which are associated with decreased quality of life and increased economic health burden. Complications are divided into early (up to 30 days after surgery) 
and late (more than 30 days after surgery).

The most common types of ostomy connect either small intestine (ileostomy or jejunostomy) or large intestine (colostomy) to abdominal wall. Other ostomies that are not very common are gastrostomy, ureterostomy, cystostomy and urethrostomy. It could be permanent or temporary. Temporary ones can be closed without a major laparotomy when it is no longer required. Major indications of ileostomy include diffused bowel injury carcinoma colon, carcinoma rectum, and inflammatory bowel disease. Colostomy is employed in colonic obstruction primarily due to cancer of distal colon or rectum, anorectal carcinoma, rectovaginal fistula and perforation with peritonitis. Jejunostomy is done mostly in carcinoma of stomach or upper gastrointestinal tract carcinomas like hypopharynx, oesophagus [1]. In this study, an attempt was made to identify common ostomies and their indications in a tertiary care setup.

\section{Aims and Objectives}

The purpose of the present study was to classify ostomies based on organs and to analyse the aetiology for creation of ostomy in surgical patients.

\section{Methods and Materials}

This is a retrospective observational study conducted at Saveetha Medical College and Hospital, over two years, from January 2017-January 2019. All patients with ostomies were included. Hospital records were perused to collect data. The data analysis was done in Microsoft Excel. The Institutional Review Board of Saveetha Medical College and Hospital has given approval for the project.

Inclusion criteria:

- All patients with a newly created stoma (in this admission).

- We included both gastrointestinal and genitourinary stomas.

- All stomas irrespective of indication was included in the study. Exclusion criteria:

- We excluded stomas in patient operated elsewhere.

- We excluded patients undergoing revision of existing stomas.

\section{Results}

In the present study there were 29 patients who had ostomies over a period of two years. There were 9 females and 20 males (Figure 1) ranging from 21 to 80 years of age, commonest age group for ostomies was 51 to 60 years (Figure 2).

There were 6 cases of ileostomy, 6 cases of colostomy, 13 cases of feeding jejunostomy, 2 cases of gastrostomy, 1 case of ureterostomy and 1 case of urethrostomy (Figure 3).

Most common indications for these ostomies were malignancy (75.90\%), trauma (6.90\%) and others (17.20\%). Others included small bowel gangrene (2 persons), duodenal perforation (1 person) and urology causes like urethral stricture (1 person) and neurogenic bladder (1 person) [Table 1]. 


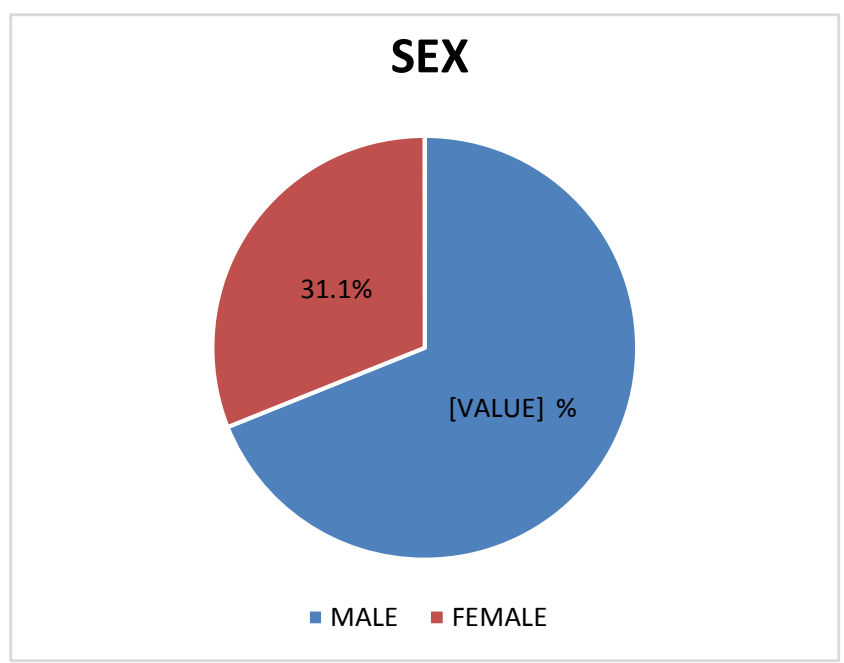

Figure 1. Shows gender distribution of ostomies.

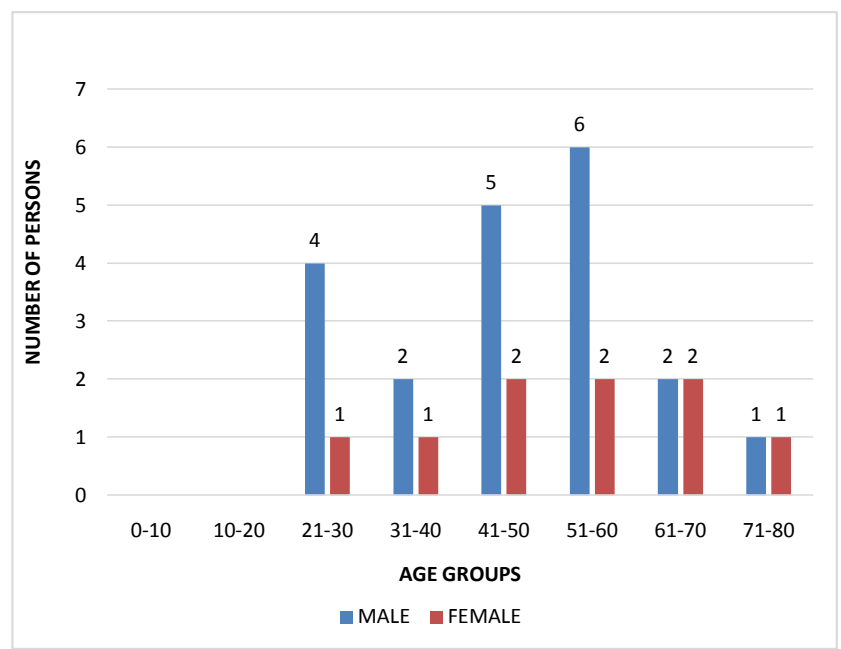

Figure 2. Shows age distribution of ostomies.

\section{TYPES OF OSTOMIES}

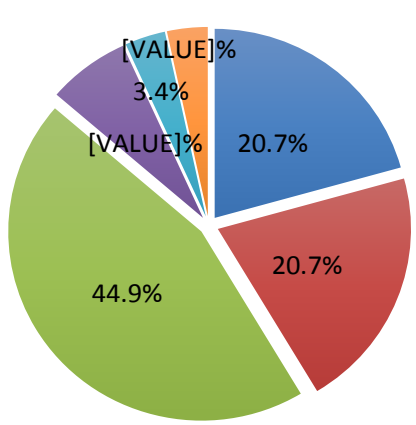
- ILEOSTOMY
COLOSTOMY
JEJUNOSTOMY
- GASTROSTOMY
- URETEROSTOMY
- URETHROSTOMY

Figure 3. Shows the different types of ostomies. 
Table 1. Shows the indications of ostomies.

\begin{tabular}{ccc}
\hline Indications & No of persons & Percentage \\
\hline Malignancy & 22 & $75.90 \%$ \\
Trauma & 2 & $6.90 \%$ \\
\hline Others & 5 & $17.20 \%$ \\
\hline
\end{tabular}

Though the commonest age group for ostomies was 51 - 60 years, malignancy was common in the age group of 40 to 50 years (Figure 4). Trauma was common in the age group of 21 to 30 years.

Of the 29 ostomies done, 22 were for malignancy. The indications for ostomies amongst the malignancy were carcinoma of stomach (6 cases), rectum (5 cases), colon ( 5 cases), hypopharynx (3 cases) and oesophagus (3 cases) [Figure 5].

\section{Discussion}

There were only sporadic records of ostomy surgery before 1700s. All through the $18^{\text {th }}$ century, accepted treatment of bowel perforation was to close any open abdominal wound and "trust in the best". This treatment plan was associated with high death rates. Most stomas were really fistulas that grew spontaneously following bowel perforation. One specialist noticed the relationship between spontaneous fistula formation and patient survival and expressed in his journal that perhaps surgeons should "take an exercise from natural force" and build arranged stomas in such cases. In the year 1706 a battlefield wound resulted in a prolapsed colostomy and it was the first ever stoma recorded. In 1793, an imaginative surgeon did colostomy on a 3-day old baby with an imperforate anus. The surgical procedure was effective and the patient lived to the age of 45 years. Ileostomy was relatively an advanced procedure and was first performed in nineteenth century for a patient with a blocking lesion in the ascending colon [2]. (Figure 6) As far as the recent advances go, the pouching system that we know today is a disposable product made of skin friendly, water repellent, cloth like material covering film laminates.

Ileostomy or colostomy is an artificial opening made in the small intestine or large intestine to divert faeces and flatus outside the abdomen, where it passes into an external outpouching system. Depending on the cause for which diversion has been made a stoma may be temporary or permanent. An ileostomy is usually placed in right iliac fossa and the effluent is usually liquid. End colostomy is usually sited in left iliac fossa, whereas a transverse colostomy is brought out in right hypochondrium and the effluent is solid. Ileostomy patients are more likely to develop fluid and electrolyte imbalance. The types of ileostomy are loop and end ileostomy. In loop ileostomy, a loop of small intestine is pulled out through the cut in the abdomen. This section of intestine is opened and stitched to the skin to form a stoma. In these cases, the stoma will have two openings, although, one may not be able to see both. One opening is active through 


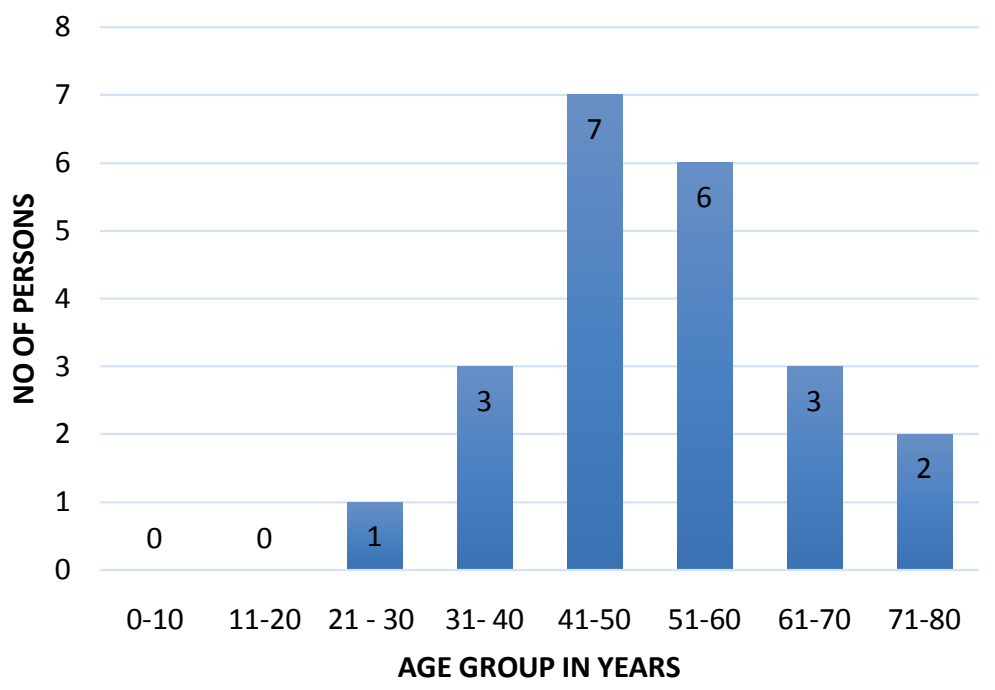

Figure 4. The distribution of malignancy in different age groups.

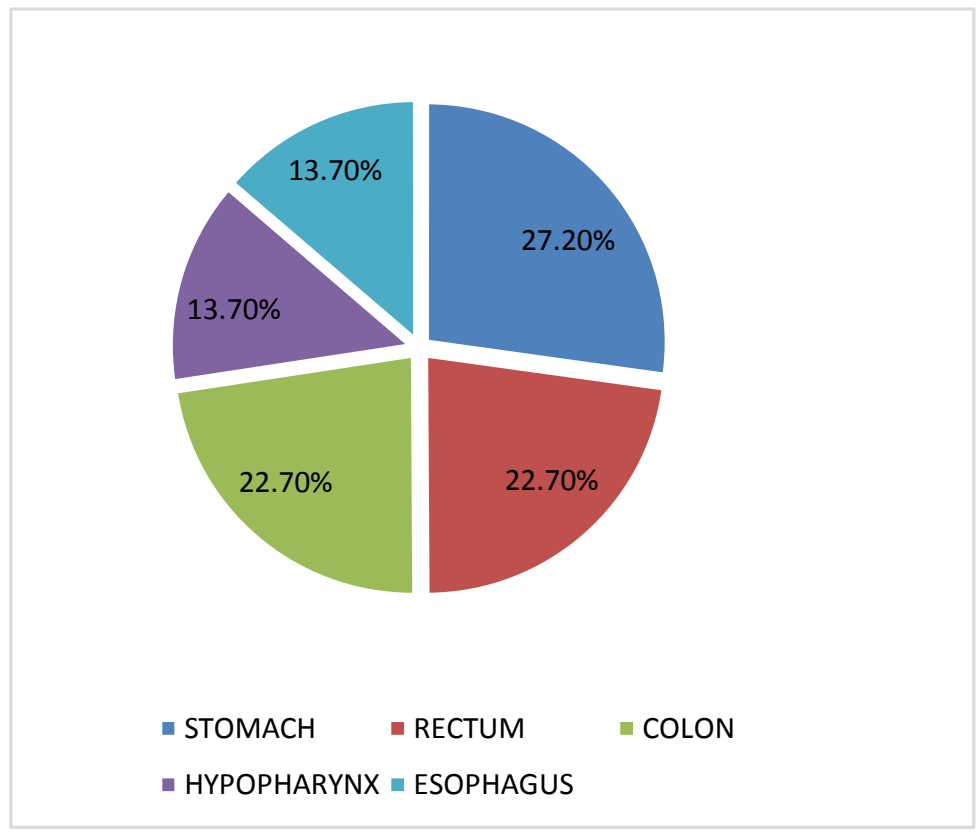

Figure 5. Indications for ostomies in malignancy.

which waste products leave the body and the other one is connected to the inactive part of bowel. The loop ileostomy is usually temporary and can be reversed during second surgery at a later date. It's often used for defunctioning a low rectal anastomosis after anterior resection of rectum or an ileoanal pouch. The advantage of loop ileostomy over a loop colostomy are bowel can be brought to surface easily and the absence of odour [3].

In an end ileostomy the whole of colon is removed through an incision in the abdomen. Then, the end of ileum is brought out of the abdomen through a smaller incision and stitched on to skin to form a stoma. Over time, the stitches dissolve and the stoma heal on to the skin. This type of ileostomy is usually but 


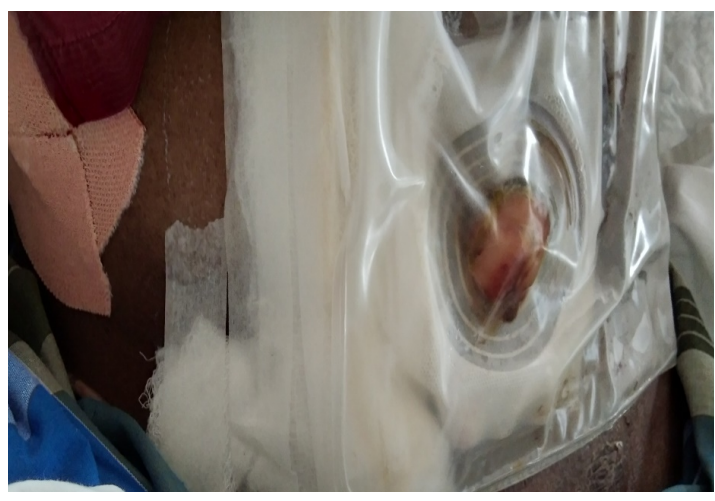

Figure 6. Colostomy.

not always, permanent. It's done in cases where total proctocolectomy is done like Ulcerative colitis, Crohn's disease, Familial polyposis coli. It can be done even after subtotal colectomy without anastomosis, where it can be later reversed [3].

The different types of colostomy are loop, end and double barrel colostomy. In loop colostomy, a loop of bowel is pulled out onto abdomen and held in place with an external device. The intestine is then sutured to the abdomen and two openings are made in one stoma. One opening for stool and the other for mucus. This type of colostomy is usually used in emergencies and is a temporary stoma. End colostomy is formed after an abdominoperineal excision of the rectum for rectal cancer or as a part of Hartmann's procedure, bringing the divided colon through right iliac fossa incision. The colonic margin is then sutured to the adjoining skin. Colostomy in Hartmann's procedure following a large bowel resection, the distal bowel is closed and left in situ and the proximal end is brought out as an end colostomy. It's done for emergency resection as in volvulus or diverticular perforation [4].

Double barrel colostomy, the bowel is cut and both ends are brought out onto the abdomen. Only proximal stoma is functioning. The colon is divided so that both ends can be brought separately to the surface with a skin bridge intervening. Temporary colostomy indications are distal bowel obstruction, defunction a low rectal anastomosis, following traumatic injury to rectum or colon, fulminant colitis. Permanent colostomy indication is rectal carcinoma excision, where end colostomy is done.

Stomal complications are quite common. A complicated stoma can cause social, domestic as well as psychological problems. On occasion these complications need surgical revision. Sometimes this can be done with an incision immediately around the stoma, but on occasion reopening of abdomen and freeing up the stoma is required. Early complications are those occurring in first postoperative month. It can be local skin problems like skin irritation and excoriation, stoma retraction, bleeding, parastomal abscess, complete necrosis and metabolic disturbances. Late complications appear after first postoperative month. Those are stenosis, prolapse and parastomal hernias. Skin irritation is due to poor stoma siting. It is a result of chemical dermatitis or frequent appliance changes or 
fungal irritation by candida albicans or may be even due to abscess [4].

In the study done by QA Ahmed et al thirty-five stomas out of eighty-five developed stoma related complications. Skin excoriation and ulceration were most common, it was more common in ileostomy than colostomy. Painful skin with ulceration makes it difficult to apply the ostomy bag and cause problems in handling the effluent. Local skin problems are quite common and can be avoided by early application of stomahesive methyl cellulose paste with proper sized bag. Treatment includes Zinc oxide paste and keep it dry it the ulcer heals.

Most of the complications are due to lack of experience and surgery done in emergency. A surgeon whose is trained, experienced and observes all technical details usually give good results. Complications need to be avoided as increase in their rates can give rise to economic burden to both patients and health sector. Moreover, reduction of complications can have a positive effect on the quality of life of the patients.

Jejunostomy and gastrostomy are one of the methods of enteral feeding. Gastrostomy is now used for enteral feeding purpose only. It is done when feeding is required for more than one month. Indications are oesophageal cancer, pharyngeal carcinoma, trauma, sepsis, head and neck surgeries and severe malnutrition.

Types of gastrostomy:

- Based on duration of use which is temporary or permanent.

- Based on lining which is mucus lined (permanent) and serosa lined (temporary).

- Based on technique:

a) Stamm temporary gastrostomy: After opening the abdomen, anterior wall of stomach is opened. Feeding tube is placed in position. Two layers of purse string sutures are put around the tube. Wound is closed.

b) Percutaneous endoscopic gastrostomy-now becoming common method.

c) Janeway's mucus lined permanent gastrostomy is done by making a tunnel in stomach wall.

Problems in gastrostomy:

a) Tube related like leakage, malposition, displacement, blockage, breakage, erosion of skin infection.

b) Gastrointestinal complications like aspiration and pneumonia, diarrhoea, bloating, abdominal cramps, nausea, vomiting, and constipation.

c) Metabolic or biochemical complications like electrolyte disorders, vitamin, mineral, trace element deficiencies and drug interactions.

d) Infective, it could be exogenous or endogenous.

Jejunostomy for enteral nutrition is becoming more popular because of its comfort, easy to do, can be kept for long time, lesser complications than gastrostomy. Indications are same as gastrostomy. Types are Witzel jejunostomy in which site of jejunostomy is $30 \mathrm{~cm}$ from duodenojejunal junction and Needle jejunostomy by using catheter of small gauge.

When created urinary stomas are created, the urine does not go to the blad- 
der. The urine is rerouted through opening on the abdomen created by a surgeon. Ureterostomy is a urinary stoma in which ureter is attached to skin's surface through a small opening in the abdomen. Indications include bladder cancer, spinal cord injury, malfunction of bladder.

In the present survey the number of ostomies over a period of two years were less (twenty-nine cases) compared to the study done by QA Ahmed et al where the number cases were eighty-five. In this study, we found that $68.9 \%$ of the study population were males which correlated with study done by QA Ahmed et al. who had $73 \%$ of the study population as males. While the maximum clustering of cases in this analysis was in the age group of $51-60$ years, whereas in the study done by QA Ahmed et al the commonest age group for ostomies was 21 - 30 years.

In the present study the commonest ostomy done was feeding jejunostomy, followed by equal number of cases of ileostomy and colostomy (20.7\%) but in the study done by QA Ahmed et al colostomy was common. According to this survey the commonest indication for the ostomies were advanced malignancy which was in contrast to study done by QA Ahmed et al in which main indications were intestinal tuberculosis and enteric perforation.

\section{Conclusion}

Males were two times more likely to have a stoma than females. Maximum clustering of cases was in age group 51 - 60 years. The most common type of ostomy in our study was feeding jejunostomy, however, it was followed by equal number of cases of ileostomy and colostomy. The commonest indication for creating a stoma was malignancy in our study.

\section{Limitations of the Study}

The study duration is short, the sample size is small and hence we are unable to provide data about complications and follow up at this moment.

\section{Conflicts of Interest}

The authors declare no conflicts of interest regarding the publication of this paper.

\section{References}

[1] Ahmad, Q.A., Kamran, S.M., Muneera, M.J., et al. (2010) Indications and Complications of Intestinal Stomas. Biomedica, 26, 144-147.

[2] Doughty, D.B. (2008) History of Ostomy Surgery. Journal of Wound, Ostomy and Continence Nursing, 35, 34-38. https://doi.org/10.1097/01.WON.0000308617.94131.f8

[3] Gordon, L.C. and Jonathan, E. (2018) Small Intestine. In: Norman, S., Ronan, O. and Colonnel, P., Eds., Bailey and Love's Short Practice of Surgery, 27 ed., CRC Press, Florida, 1254-1255.

[4] Gordon, L.C. and Jonathan, E. (2018) Large Intestine. In: Norman, S., Ronan, O. and Colonnel, P., Eds., Bailey and Love's Short Practice of Surgery, 27 ed., CRC Press, Florida, 1277-1278. 